\title{
Do They Really "Know Nothing"? An inquiry into ethnobotanical knowledge of students in Arizona, USA
}

\author{
Colleen M. O’Brien
}

\section{Education}

\begin{abstract}
Recent research indicates differences in what children know and how they learn about plants when compared to their parents and grandparents. Ethnobotanical research was conducted with students in Ajo, Arizona, U.S.A, a rural town that has undergone vast social, economic, and political changes. The interviews included free lists and an identification exercise using video clips of Sonoran Desert plants. Students have a limited knowledge of the plant domain listing an average of five plants, the majority of which were non-native. Students correctly identified an average of $4+/-2.65$ out of 20 Sonoran plants. Size and integration into the market economy were limiting factors in the identification of particular plant referents. Students who reported learning about the desert from experience or a person had higher identification scores than those who named other means. The research results highlight how cultural knowledge about local plants can be applied to educational programs that promote experiential learning.
\end{abstract}

\section{Introduction}

In subsistence-based and small-scale agricultural communities where people depend upon foraging and farming for survival, children learn ecological knowledge through various means within the social contexts of their daily lives. Subsistence practices such as gathering wild foods or hunting provide critical skills required to live in particular environments and impart what Raffles (2002) refers to as an "intimate" knowledge grounded within local landscapes. Local ecology is thus embedded within material artifacts, stories, and rituals, reproduced within daily practices, and passed along from generation to generation during the process of socialization. For example, Stross found that Mayan children can name and identify upwards of 100 unique plants by age 12 (Stross 1973). Hunn (2002) posits that this "precocious acquisition" of plant knowledge indicates an innate predisposition to na- ture learning, if provided the social and ecological opportunities in which to learn. One key question is whether or not such opportunities still exist.

Global political and economic shifts have had profound effects on subsistence-based populations resulting in changes in consumption patterns and labor, which often diminish direct dependence on the local environment for survival. Understanding the effects of these processes on populations has increasingly been the topic of anthropological research. One focus is to understand how social, political, and economic changes affect the acquisition and transmission of local ecological knowledge. Ethnobotanists in particular have concentrated on whether ecological knowledge is being lost or changed in the face of shifting economies and market integration (see Godoy, et al. 1998, Ohmagari \& Berkes 1997, Reyes-Garcia et al. 2007, Ross 2002, Zarger \& Stepp 2004, Zent 2001). The results of such studies have been mixed. Godoy et al. (1998) found that market integration among the Tawahka Indians of Honduras has different effects on knowledge depending on the type of market. Agriculture and wage labor were associated with less knowledge and the

\section{Correspondence}

Colleen M. O'Brien, Department of Anthropology, University of South Florida, 4202 E. Fowler Avenue, Tampa, Florida, U.S.A. cobrien@cas.usf.edu

Ethnobotany Research \& Applications 8:035-047 (2010)

Published: March 3, 2010 
sale of timber/non timber forest products with more. On the other hand, botanical knowledge has persisted among Tzeltal Maya children because the ways in which children acquire such knowledge has remained relatively the same despite social, political, and economic changes in the region (Zarger \& Stepp 2004).

Researchers have posited myriad reasons to explain changes in plant knowledge including transitions from subsistence to wage labor, limited nature access and exposure, and lack of motivation among others (Heckler 2002, Krech 2005, Ross 2002, Zent 2001). Another proposed theory is that today people acquire knowledge about the natural environment differently than in the past and this is affecting the content and depth of what people know about nature. Throughout human history, people's primary means of transmitting ecological knowledge has been through informal learning experiences, songs, and stories, passed from one generation to the next while harvesting or gathering wild foods. The telling of stories is one of the first ways that humans transmitted and stored information before the advent of written language or computers (Donald 1991). Oral traditions were a storage vessel and a vehicle for cultural knowledge including ecological and historical information. For instance, the O'odham creation tale "Earth Magician" names and provides ecological information for seven desert foods including mesquite pods, cactus, corn, grass, melon, squash and beans (Nabhan 2002). Stories are embedded in the local landscape and so they impart social memory, historical, and spatial information (see Basso 1984, Gordillo 2004, Rosemann 1998).

Today the primary cultural storyteller has become the media, particularly television. Pergams and Zaradic found that nature-based recreation has been largely replaced by "videophilia", which they define as "the new human tendency to focus on sedentary activities involving electronic media."(Pergams \& Zaradic 2006, 2008). Media not only provides entertainment, but children also rely on television, Internet, and videos for learning about the natural environment. The problem is that media content is often focused on faraway places rather than local environmental information or concerns. So children may not learn that practicing conservation in their local ecosystem is as important as protecting tropical rainforests. Furthermore, children attend school for longer periods of time than in the past and acquire ecological information in formal classroom settings rather than during daily practices of tending a garden or foraging for wild foods. Due to these changes, children have become the focus of studies on the acquisition, transmission, and persistence of ecological knowledge. Research indicates that children know much less than their parents or grandparents about the natural environment (Kellert 2002, Louv 2006, Nabhan 1994). Authors and news media have developed terms such as "nature deficit disorder" (Louv 2006) lending medical language to the phenomenon of younger generations becoming culturally and physically disconnected from their natural habitats. This has been deemed a crisis by many, and researchers have set out to study it at length. Studies concerning American children's knowledge of local ecology have traditionally been conducted within the fields of biological and environmental education. Research in this area has focused on general categories, such as the ecosystem concept or awareness about environmental problems like global warming, rather than on particular domains of knowledge such as plants.

There are few studies in United States that focus specifically on children's botanical knowledge. A study on children's ethnobotanical knowledge conducted in Berkeley, California in the late 1970s found that by age twelve, American children lagged far behind Mayan children in acquiring generic, specific, and varietal distinctions in plant species (Dougherty 1979). Ethnobotanical research conducted in Arizona revealed a marked generational change in the ability of children to name plants, describe how to use them, or provide ecological information about them in comparison to their parents and grandparents (Nabhan \& St.Antoine 1993, O'Brien 2008). Ethnobotanical knowledge of elementary and college students conducted in South Carolina (Cooper 2008, Wagner 2008) also found a relatively low level of knowledge about specific plant domains especially for wild vegetation. In order to better understand how ecological knowledge is changing in younger generations, ethnobotanical research should focus on the specifics of how knowledge is changing. Such work would differentiate between types of knowledge like naming versus identification and skills, and would identify variation in knowledge among specific plant domains. Besides investigating the content of knowledge, it is also necessary to focus on the acquisition of knowledge and skills. Identifying the importance of key experiences for learning about nature during childhood would underscore the importance of incorporating place-based experiential education programs into school curriculum.

Ethnobotanical research was conducted in the Ajo Unified School District in Ajo, Arizona, a rural town 30 miles north of the US-Mexico border in the heart of the Sonoran Desert. The research framework encompasses cognitive and ethnoecological theory and methods in order to identify plant naming and identification abilities and the learning experiences associated with acquiring such information. The research reported here is taken from a larger ethnographic study comparing inter-generational variation in ethnobiological knowledge and differences in learning among children, adults and elders.

\section{Background}

The Sonoran Desert has a long history of human habitation dating back ten thousand years (Sheridan 2000). In order to survive in such an environment, one had to have extensive knowledge of desert ecology including wild 


\section{O`Brien - Do They Really "Know Nothing"? An inquiry into ethnobotanical knowledge of students in Arizona, USA}

foods, weather patterns, and water sources. The Tohono O'odham were semi-nomadic seasonal farmers, residing near mountain springs in winter and along arroyos, or riverbeds, in the summer. The Tohono O'odham perfected these skills and lived and thrived in the region in this manner for an estimated four hundred years. In the arroyos, they would dig ditches to collect water runoff from alluvial floodplains brought by seasonal summer monsoon rains in order to irrigate their crops (Dobyns 1972, Fontana \& Shaefer 1981). In addition to farming, they hunted local game and gathered a wide variety of wild plant foods including cactus, cactus fruits, and mesquite pods, which they ground into flour. In the $16^{\text {th }}$ century, the arrival of Europeans brought great changes to the region. Europeans carried with them deadly epidemics that killed many Native Americans. Their arrival drastically changed the existing social and cultural structures of Native Americans by forcing them to leave their native lands and requiring their children to attend boarding schools. The colonial settlements brought new food sources to the region such as wheat and cattle, which would profoundly change the landscape and the livelihoods of the desert people. Although landscapes are in a continuous state of change from ecological and human induced factors, in the middle 1800s, overgrazing, deforestation, and urban and agricultural development increased drastically in the region. The political landscape was changing as well. In 1848, land that is now southern Arizona was transferred from Mexico to the United States under the Gadsden Purchase. Additional frontier legislation including the Homestead Act and the Desert Land Act encouraged even further development.

Ajo, Arizona was settled in 1847 as part of this development, by Tom Child's Sr. on his way to Magdalena, Sonora, Mexico. Ajo was established shortly after as a mining town, removing primarily copper, but also silver and turquoise from the nearby mountains. When the mine expanded in 1910, Ajo began to draw a multi-ethnic population of Tohono O'odham, Mexican, and Anglo men to work wage labor jobs in the mine or on nearby cattle operations. In 1931, the mine became the New Cornelia Branch of the Phelps Dodge Mining Company and at its peak it employed 13,000 people. The mine jobs were stratified by ethnicity with the Anglos working as mine managers in white collar jobs, the Mexicans working as mine engineers, and the Tohono O'odham working the most dangerous jobs as blasters. This social stratification formed the basis for the building of the town, the design of the neighborhoods, and many of the social repercussions of such order remain today. Although cultural sharing occurred within this tri-ethnic population, there were significant social pressures to abandon existing subsistence practices in order to fit into the new economy. Native American settlements on the outskirts of Ajo were discouraged by no longer sending buses out to collect children for school. Mine jobs shifted subsistence from farming to wage labor. A Phelps Dodge company store provided prepackaged and processed foods, which mine workers could buy on credit. Such foods replaced many wild and cultivated varieties of desert foods that were formerly eaten.

When the mine closed in 1986 it devastated the local economy, forcing many to flee to nearby urban centers of Tucson and Phoenix. According to the most recent census in the area, Ajo's population is 3,705 (US Census 2000). The few thousand people who remain have survived on unemployment checks or by working in the service industry and federal government jobs. Highway 85, the main road through town, provides access to Organ Pipe National Monument, Cabeza Prieta Wildlife Refuge, the Tohono O'odham casino, and the popular Mexican beach destination of Puerto Peñasco (Rocky Point) from Phoenix or Tucson. Many Ajo businesses take advantage of the tourist traffic along Highway 85 by selling gas, liquor and beer, Mexican insurance, and convenience store food.

The dramatic changes that occurred during its transition from a company mining town to an economically depressed area, dependent upon the service industry and tourism, transformed social practices as well as the local landscape. Since economic shifts are associated with marked changes in ecological knowledge (Godoy et al.1998, Guest 2002), Ajo is an excellent site for studying how plant knowledge and acquisition are changing.

\section{Methods}

The research participants included a multi-ethnic (Anglo, Mexican, and Tohono O'odham) population of 110 students between the ages of 12 and 20 with a mean age of 15. All of the students attend the Ajo Unified School. The population is $66 \%$ male and $44 \%$ female. Thirty-four percent of the students are monolingual in English, 60\% are bilingual English and Spanish, and 6\% are trilingual in English, Spanish, and Tohono O'odham. On average, the participants have lived in Ajo or one of the nearby villages on the Tohono O'odham reservation for 11 years. The interviews took place at the Ajo Junior High and High School and were conducted by myself or one of three research assistants trained in ethnographic interviewing. Prior consent was obtained from the parents or guardians of all participants and from the students themselves preceding the interviews. All interviews were conducted in English or Spanish, depending upon the preference and language ability of the research participant. Since informant exhaustion is of concern in non-expert populations, especially among children, (Holmes 1998) the interviews were limited to approximately thirty minutes in length. The interviews were recorded on paper and audio tape, transcribed, and coded.

Data collection methods included structured interviews, which involve asking the same questions in the same order to each participant (Spradley 1979) and participant observation in school and at key locations in the commu- 
nity following deMunck and Sobo (1998). The interview was broken into three sections. The first task employed free listing, a technique used to identify culturally salient items within a particular domain, which in this case, was the plant domain (Weller \& Romney 1988). Students were asked to "name all of the plants that you know". Free lists are often used as a starting point in research in order to create a data collection tool, such as a survey or pile sorting exercise, to be used later in one's study. However, they have also been used by researchers as a primary analytical tool (Fleisher \& Harrington 1998), to answer a specific research question, or to determine knowledge variation. In this case, the purpose of the free listing exercise was not to seek "correct answers" but rather to obtain the following data points for comparison: 1) plants that are considered culturally salient; 2) non-native versus native plants; and 3) specificity with regard to taxonomic levels used in naming. Although narrowing domains often leads to more focused categories (Quinlan 2005) such as "grasses" or "cacti", the domain was kept broad as "plants" instead of "Sonoran Desert plants" in order to provide a view of the overall domain (and the most important sub-domains within) and to allow for a comparison of non-native and native species that comprised their lists. This differentiation would be useful in identifying local versus non local knowledge about the plant domain and would give insight into how students are learning about plants. The idea being that listing mostly non-native species would suggest that the students are learning in "vicarious or indirect manners" (Kellert 2002) such as watching the Discovery Channel rather than in situated experiences such as planting a desert garden. Once the free lists were obtained, the second part was a visual elicitation task (Johnson \& Griffith 1998) that required students to view a series of twenty video clips (see Table 1) of native (Sonoran Desert) plants on a laptop or a small portable DVD player. The plants chosen to include in this study were identified as culturally salient through previous interviews with a group of Anglo, Mexican, and Tohono O'odham adults and elders who were considered by the community to be knowledgeable about plants (O'Brien 2008).

The videos consisted of thirty second clips in .wmv format that showed a native plant in its various life stages and in typical ecological settings. [Copies of these videos serving as voucher specimens were provided to the National Park Service, Organ Pipe Cactus National Monument for their research library collection which is available to all researchers and park staff.] Using video that illustrated various life stages was important for identification because a plant like the ocotillo enters a leafless dormant state during the dry season, but then takes on an entirely new ap-

Table 1. Names of plant used for video elicitation of multi-ethic students between the ages of 12 and $20(\mathrm{~N}=110)$ in the Ajo Unified School, Arizona.

\begin{tabular}{|c|c|c|c|}
\hline English & O'odham & Spanish & Scientific \\
\hline agave & a'o't & agave & Agave spp. \\
\hline beargrass & moho & palmilla & Nolina microcarpa S. Watson \\
\hline bird pepper & tcirtipin & chiltepin & Capsicum frutescens $\mathrm{L}$. \\
\hline brittlebrush & tuhar & incienso & Encelia farinosa A. Gray ex Torr. \\
\hline buckhorn cholla & hanam & cholla & Opuntia acanthocarpa Engelm. \& J.M. Bigelow \\
\hline cholla, teddy bear & ha:nam & cholla & Cylindropuntia bigelovii (Engelm.) F.M. Knuth \\
\hline creosote, greasewood & ségai & hediondilla & Larrea tridentata (Sessé \& Moc. ex DC.) Coville \\
\hline devil's claw & ihu'k & uña de gato & Proboscidea parviflora (Wooton) Wooton \& Standl. \\
\hline foothills palo verde & ko'okmadk & palo verde & Cercidium microphyllum (Torr.) Rose \& I.M. Johnst. \\
\hline ironwood & ho'idkam & palo fierro & Olneya tesota A. Gray \\
\hline jojoba & hohowai & jojoba & Simmondsia chinensis (Link) C.K. Schneid. \\
\hline mesquite & kui & mesquite & Prosopis spp. \\
\hline mormon tea & kawaiisu & popotillo & Ephedra spp. \\
\hline ocotillo & mélhoki & ocotillo & Fouquieria splendens Engelm. \\
\hline organ pipe cactus & tcutcuis & pitahaya dulce & Stenocereus thurberi (Engelm.) Buxb. \\
\hline prickly pear & nohwi & nopal & Opuntia engelmannii Salm-Dyck ex Engelm. \\
\hline sacred datura & kótdop & datura & Datura spp. \\
\hline saguaro & ha:canyi & sahuaro & Carnegiea gigantea (Engelm.) Britton \& Rose \\
\hline tepary bean & bawi & teparia & Phaseolus acutifolius A. Gray \\
\hline wolf berry, squaw berry & kohm & tomatillo & Lycium spp. \\
\hline
\end{tabular}




\section{O'Brien - Do They Really "Know Nothing"? An inquiry into ethnobotanical knowledge of students in Arizona, USA}

pearance by quickly sprouting leaves and bright red flowers shortly after the monsoon rains. Video also provided ecological clues such as showing plants that grow in arroyos or south facing slopes, information which could help in identification of the referent. Although visual stimuli that replace the actual plant referent have been used often in ethnobotanical studies, these substitutes are not without problems. One drawback of video is it does not allow one to touch, taste, or smell the plant during identification. However, Johnson and Griffith (1998) point out that for large plants such as desert succulents, photos or videos are often more practical than voucher specimens (e.g., the organ pipe cactus, Stenocereus thurberi, can reach heights of 23 feet, with branches averaging 6 inches in diameter). Using video as an elicitation method was also more portable and practical than a plant trail since there was not one close by. After watching each video clip, the students were asked to name the plant and to elaborate on where they had seen the plant. Prompts were used to solicit additional information including ecological and cultural knowledge by asking "where are the places that you see this plant" or "have you eaten this"? The third part of the interview consisted of open-ended questions asking students how they learn about the desert, how they would find out an answer about the desert, free time activities, and general demographic information such as age, years of residence, household composition, and languages spoken.

The free lists were analyzed using ANTHROPAC (Borgatti 1996) software. ANTHROPAC combines all of the participant's lists and calculates frequencies and ranks for each item. ANTHROPAC also calculates a salience score, a combination of the item's frequency (how often it appears on a list) and its rank (where it appears on the list). Due to multiple common names for plants and animals and respondents answering in Spanish, English or Tohono O'odham, the free lists analysis was completed with uncoded lists, and then duplicate items were recoded into one category. This coding scheme was done in order to include multiple names for one referent such as greasewood, creosote, rain tree, and hediondilla (all common names for Larrea tridentata) into one free list item. A local native speaker of Tohono O'odham who is also fluent in English and Spanish was consulted when recoding as to be certain of multiple plant names.

Data from the identification exercise, questions regarding learning, and demographic information were entered into SPSS 15.0 software to calculate frequencies, to tabulate results of the identification exercise by demographic information, and to test for associations between identification scores and variables. An ANOVA analysis that determines if there is a significant variance in means between two groups was used to test for associations. All plant referents were added to the database and each student respondent was assigned a unique numeric code as an identifier. The data were then transcribed from the inter- view sheets. The SPSS data were coded a 0 if the respondent did not know the name of a referent or provided an incorrect response, a 1 if they knew the life form or domain name such as "tree", and a 2 if they knew the generic or specific varietal name such as "organ pipe cactus". Overall frequencies were computed and only specific identifications (those coded a 2) were counted in the overall identification scores reported here. Analysis for each plant referent was also computed in order to determine the most and least identified plants by the group as a whole. Interviews were transcribed and thematically coded by hand in order to identify qualitative data on learning environments, outdoor experiences, and cultural knowledge. The qualitative data were compared with quantitative data in order to explain and add ethnographic context to the study results.

\section{Results}

The students as a group named a total of eighty-five plant items. On average, students named five plants each. The most salient plants (see Table 2) were cactus, saguaro, and palo verde. Of the twelve most salient plants, nine are folk generic or specific varietal terms and three are life form or domain terms. Excluding the domain names of "cactus", "tree", and "flower", only "rose" and "oak" are non-native to the Sonoran Desert.

Although not the most salient, non-native items made up $58 \%$ of the plant lists. Eighty-nine percent of the plant names were folk specific while $11 \%$ were life form names (e.g., tree rather than mesquite tree). Members of two subdomains, cactus and trees/woody shrubs, comprised the majority of the items on their lists (see Table 3 ).

Table 2. Free lists of plants ${ }^{1}$ named by multi-ethic students between the ages of 12 and $20(\mathrm{~N}=110)$ in the Ajo Unified School, Arizona.

\begin{tabular}{|l|c|c|}
\hline Plant & Frequency $^{2}$ & $\begin{array}{l}\text { Saliency } \\
\text { (Smith's S) }\end{array}$ \\
\hline Saguaro & 45 & .327 \\
\hline Cactus & 41 & .317 \\
\hline Palo Verde & 33 & .192 \\
\hline Rose & 29 & .174 \\
\hline Cholla & 23 & .143 \\
\hline Ocotillo & 21 & .132 \\
\hline Mesquite & 22 & .105 \\
\hline Tree & 15 & .103 \\
\hline Prickly Pear & 16 & .085 \\
\hline Flower & 14 & .085 \\
\hline Oak & 11 & .057 \\
\hline Organ Pipe & 11 & .057 \\
\hline
\end{tabular}

1. Items in the table are sorted by salience.

2. Only items with a frequency of greater than 10 were selected for the table. 
Table 3. Examples of free list items by domain ${ }^{1}$ named by multi-ethic students between the ages of 12 and 20 $(\mathrm{N}=110)$ in the Ajo Unified School, Arizona.

\begin{tabular}{|l|l|l|l|}
\hline Cactus & $\begin{array}{l}\text { Tree/woody } \\
\text { shrub }\end{array}$ & Ornamental & Other $^{2}$ \\
\hline Saguaro & palo verde & Rose & Grass \\
\hline Cholla & Mesquite & Sunflower & Marijuana \\
\hline $\begin{array}{l}\text { Barrel cac- } \\
\text { tus }\end{array}$ & Oak & Fern & $\begin{array}{l}\text { Venus } \\
\text { Flytrap }\end{array}$ \\
\cline { 1 - 2 } $\begin{array}{l}\text { Organ pipe } \\
\text { cactus }\end{array}$ & Pine & \\
\cline { 1 - 2 } $\begin{array}{l}\text { Prickly pear } \\
\text { cactus }\end{array}$ & Creosote & & \\
\cline { 2 - 2 } & Maple & \\
\cline { 2 - 2 } & Palm & \\
\hline
\end{tabular}

1. Included are items listed by 3 or more students.

2. The "Other" domain includes agricultural, weeds, vines, and ivy.

Table 4. Identification frequencies of plants correctly identified by multi-ethic students between the ages of 12 and 20 $(\mathrm{N}=110)$ in the Ajo Unified School, Arizona.

\begin{tabular}{|c|c|c|c|c|}
\hline $\begin{array}{l}\text { Percent } \\
\text { Correct }\end{array}$ & English & O'odham & Spanish & Scientific \\
\hline $78 \%$ & saguaro & ha:canyi & sahuaro & Carnegiea gigantea (Engelm.) Britton \& Rose \\
\hline $53 \%$ & prickly pear & nohwi & nopal & Opuntia engelmannii Salm-Dyck ex Engelm. \\
\hline $46 \%$ & $\begin{array}{l}\text { organ pipe cac- } \\
\text { tus }\end{array}$ & tcutcuis & pitahaya dulce & Stenocereus thurberi (Engelm.) Buxb. \\
\hline $42 \%$ & palo verde & ko'okmadk & palo verde & Stenocereus thurberi (Engelm.) Buxb. \\
\hline $40 \%$ & mesquite & kui & mesquite & Prosopis spp. \\
\hline $39 \%$ & ocotillo & mélhoki & ocotillo & Fouquieria splendens Engelm. \\
\hline $29 \%$ & $\begin{array}{l}\text { creosote, } \\
\text { greasewood }\end{array}$ & ségai & hediondilla & Larrea tridentata (Sessé \& Moc. ex DC.) Coville \\
\hline $17 \%$ & devil's claw & ihu'k & uña de gato & Proboscidea parviflora (Wooton) Wooton \& Standl. \\
\hline $14 \%$ & agave & a'o't & agave & Agave spp. \\
\hline $12 \%$ & bird pepper & tcirtipin & chiltepin & Capsicum frutescens $\mathrm{L}$. \\
\hline \multirow[t]{2}{*}{$5 \%$} & brittlebrush & tuhar & incienso & Encelia farinosa A. Gray ex Torr. \\
\hline & ironwood & ho'idkam & palo fierro & Olneya tesota A. Gray \\
\hline \multirow[t]{3}{*}{$2 \%$} & buckhorn cholla & hanam & cholla & Opuntia acanthocarpa Engelm. \& J.M. Bigelow \\
\hline & $\begin{array}{l}\text { teddy bear } \\
\text { cholla }\end{array}$ & ha:nam & cholla & Cylindropuntia bigelovii (Engelm.) F.M. Knuth \\
\hline & $\begin{array}{l}\text { wolf berry, } \\
\text { squaw berry }\end{array}$ & kohm & tomatillo & Lycium spp. \\
\hline \multirow[t]{4}{*}{$1 \%$} & beargrass & moho & palmilla & Nolina microcarpa S. Watson \\
\hline & $\begin{array}{l}\text { sacred } \\
\text { datura }\end{array}$ & kótdop & datura & Datura spp. \\
\hline & jojoba & hohowai & jojoba & Simmondsia chinensis (Link) C.K. Schneid. \\
\hline & tepary bean & bawi & teparia & Phaseolus acutifolius A. Gray \\
\hline $0 \%$ & mormon tea & kawaiisu & popotillo & Ephedra spp. \\
\hline
\end{tabular}

There were no significant differences in list length between males and females or in Anglo, Mexican, or O'odham students in the free listing exercise. When comparing list composition with demographic and behavioral data, the lists of students who reported hunting ( $16 \%$ of study participants) as a free time activity were comprised of more specific plant names and more plants native to the Sonoran Desert.

The mean score for the plant identification videos was 4 $+/-2.65$ with the lowest score a zero out of twenty and the highest eleven out of twenty. An analysis by plant referent reveals the most identified plants were saguaro, prickly pear, organ pipe cactus, and palo verde. The least identified plants were Mormon tea, beargrass, jojoba, tepary bean, and sacred datura (see Table 4).

When asked, "How do you usually learn about plants and animals?" $48 \%$ of students reported learning from people. These included fathers, grandparents, uncles, park rangers and friends. They reported learning from school and 


\section{O`Brien - Do They Really "Know Nothing"? An inquiry into ethnobotanical knowledge of students in Arizona, USA}

experience at $16 \%$ each, followed by books at $9 \%$, television at $7 \%$, and finally the Internet at $1 \%$. Mexican children named learning from a person most often (53\%) followed by Anglos (46\%) and Tohono O'odham (42\%). Television was identified most often by Tohono O'odham children (17\%) for learning about the desert and by $11 \%$ of Mexican students. None of the Anglo participants cited television as a way that they learn about the desert. When asked, when you have a question about the Sonoran Desert, how do you usually find out the answer, $57 \%$ of the students said they find out from a person while $31 \%$ cited the Internet. Books were named by $9 \%$, and experience, school, and television were only named by a few.

Students reported spending their free time playing sports $(33 \%)$, riding off road vehicles (ORVs) $(11 \%)$, watching television ( $9 \%)$, and various other activities ranging from skateboarding to listening to music. Males were five times more likely to report a desert-based activity such as riding ORVs or camping than females. Females reported more indoor activities such as watching television, reading, or talking on the phone. Students who still participate in subsistence activities like hunting reported learning more frequently from family members than from books or school. For example, $81 \%$ of students who hunt regularly reported that they would go to a person to find out an answer about the desert in comparison to $52 \%$ of non hunters.

An ANOVA test was performed on the identification scores and the demographic variables age, ethnicity, gender, household (in town versus out of town), grandparent (Do you live with a grandparent?), and languages spoken, and with the behavioral variables concerning learning (how do you usually learn?) and (how would you find out an answer?), and reported free time activities such as park visitation and hunting. Students who live with a grandparent had lower scores than those who do not, indicating an association at the $p=.10$ level. Also, students who said they learned about the desert from experience or a person had higher identification scores than those who named books, television, or school, at $p=.08$. All other variables did not show any associations at the $p=.10$ level or lower.

\section{Discussion}

The composition and length of the free lists revealed that students have a limited knowledge of the plant domain. Students free listed common names or folk classifications $89 \%$ of the time, which is consistent with Berlin's (1992) assertion that the folk taxonomic rank is the most salient conceptual grouping in plants. Tull (1994) had similar findings with children preferring to identify plants at the generic level. However, three life form names indicating a plant domain rather than folk specific name-cactus, flower, and tree, were among the most salient named items during the free list exercise. As daily intimate contact with the natural world is diminished, people tend to lose more detailed knowledge of plants and this is reflected in the cultural sa- lience of more general terms such as "tree" (Witkowski et al. 1981). Evidence of diminishing plant knowledge is also demonstrated during the identification exercise. Seventy percent of the answers during the identification exercise were incorrect or the respondent said "I don't know". Of the correct answers, $68 \%$ were folk generic or specific varietal names while $32 \%$ were life form or domain names. It has been speculated that as wild plants become less important in a culture, people will replace generic and specific names with life-form names (Berlin 1972, Tull 1994). Much like the results of Tull's (1994) study, students did not know the correct names for most of the plants included in this study, which signifies diminishing knowledge. However, for the plants that they did recognize, they answered with generic level names, rather than domains, the majority of the time. The prevalence of generic level names may decline, being replaced by life form or domain names as environmental knowledge continues to erode.

The list length, which averaged five plants, is short, considering the same group of students listed an average of 12 animals during a separate task (O'Brien 2008). List length is typically a reflection of the importance that the particular domain holds in a society (Dougherty 1978), so it appears that these students view plants as less salient than animals. Although the most salient items were native Sonoran plants, the majority of items on the lists were non-native. Students tended to name native plants first and then switch to non-native later in their lists. An apparent early exhaustion of native species in their listing signifies a shallow familiarity with the desert plant world. The exception here is students who reported hunting as a typical activity. Rather than list domain names like cactus, their lists were comprised of specific cacti such as teddy bear, jumping, prickly pear, and barrel.

The most named and identified plants share certain commonalities. The domains of cactus and trees are physically the largest on the desert landscape, which could explain their salience. Berlin (1992) has asserted that certain organisms "are so obvious in their presence they can hardly be ignored". Hunn (1999) also explains that the plants that are greater in size have an increased "perceptual salience" and are more likely to be noticed on the landscape, thus size was found to be a limiting factor in the identification of particular plant referents. The saguaro cactus, the most named and identified plant, can grow to heights over twenty feet tall. The organ pipe cactus and the palo verde are also quite large and hard to ignore on the landscape. These plants are all commonly found close to the home. An informal plant survey conducted within a one mile radius of the central town plaza of Ajo revealed that thirteen out of the twenty plants included in the identification exercise could be found in and around the neighborhoods of Ajo. The saguaro, prickly pear, organ pipe cactus, palo verde, and mesquite all grow in many yards in town and are scattered along the foothills of the surrounding mountains. The prickly pear, although not tall like the 
columnar cacti, grows to be a large plant that spreads out along washes and fence lines. Therefore, students would have exposure to these plants walking to school or in their yards and neighborhoods.

Trees were one of the most commonly named domains on free lists and were also among the most identified. This finding is consistent with an apparent cultural salience of the domain of trees for American children in previous studies (Cooper 2008, Dougherty 1979). Dougherty (1978) found that children acquire tree names at a younger age and in greater numbers than other domains indicating the significance of the tree domain. The palo verde and mesquite trees were salient on student's free lists and were correctly identified by $42 \%$ and $40 \%$ respectively.

Items in the cactus and tree domains have another commonality in that many of them have been absorbed into the local and global economy as commodity items. Prickly pear pads or nopalitos are sold fresh and pickled in grocery stores across the United States and throughout Latin America. The prickly pear fruit can be found at specialty shops in small decorative jars sold processed into jelly or syrup. Mesquite is still widely used in "southwestern style" cooking and is marketed in items such as Kentucky Fried Chicken's "mesquite chicken". The symbolic saguaro cactus is also used to advertise a variety of items from desert vacation getaways to southwestern salsa. Since Ajo has become primarily a tourist, service industry town, many of the local shops and restaurants have marketed these items as place-based local commodities. Students would have the opportunity to see these items on local store shelves and thus may explain their salience despite diminished experiences in outdoor learning activities.

The least named and identified plants have a few things in common; their previous cultural importance for food and medicine, their lack of integration into the market economy, and their smaller size. At one time plants such as Mormon tea, beargrass, jojoba, tepary bean and sacred datura were all important cultural plants for food, basket making, and ceremony among Mexicans and O'odham. Tohono O'odham and Mexicans used Mormon tea for bronchial congestion and old Anglo ranchers tell stories of using it for appetite suppression during long travels through the desert. With the shifting economy, these items have now become obsolete in a world where you can go to the local pharmacy for treatment rather than seek a cure from known plant sources in the desert. During Ajo's development boom in the early part of the 20th century, the Phelps Dodge Company built a large hospital overlooking the town where people sought medical care. Having access to rural health care lessened the necessity for homemade medical cures. There are still people in Ajo who have small kitchen gardens using various curative plants, but this is rare.
The less named and identified plants differ from the salient ones like the mesquite or prickly pear in that they have not been integrated into a market economy. Although more and more Tohono O'odham are learning to make the traditional native baskets from beargrass to sell to tourists, they are available only at Organ Pipe Cactus National Monument, Tohono O'odham trading posts, and a few specialty shops. The tepary bean, a former staple food of the Tohono O'odham is rarely eaten today despite its many health benefits. The group Tohono O'odham Community Action (TOCA) and others are working to reintroduce native foods to help combat diabetes and obesity since their high levels of fiber help to slow the absorption of sugar in the body. However, tepary beans are not yet available at local markets.

The lesser named and identified plants are also some of the smallest plants on the landscape. If some plants are less noticeable on the landscape due to their size then they will only be noted when individuals have an "intimate familiarity of experience" (Berlin 1992). Many of the activities that students reported doing in their free time do not foster intimate experiences with nature. For example, when asked about outdoor activities, students indicated they would go driving in the desert with their families or use off-road vehicles (ORVs) to go "quading", a local term for riding ORVs on undesignated trails throughout the desert lands. Although outdoors, these activities do not have the same intimacy as hiking through the desert and small plants such as the sacred datura, which grows in washes or areas collecting water runoff, can be missed while riding in a car or on an ORV.

The range of identification scores from zero to eleven indicates a high level of group variation. Hunting was found to be an important experience based activity in that students who hunt had longer lists and more native and specific list composition. Students who hunt report going with a parent or close relative such as an uncle for both subsistence and recreational purposes. Such experiences provide opportunities for social learning with knowledgeable elders. In the course of the interviews, students would often relay stories of hunting trips, explicitly describing landscapes, plants, and animals that they had learned about during their experiences. Interestingly, during the plant identification exercise, students who hunt could identify trees and cacti even before the camera zoomed in for a closer shot. They would often comment "that's a mesquite tree, I can tell by its shape". Since hunting requires an individual to stay still for long periods of time observing the environment, it instills a more intimate knowledge of the desert landscape, which can only be gained through experience.

Having both a listing and an identification exercise begs the question, were items that were named also identified? The saguaro, the most named item on the free lists, was also the most identified (correctly identified by $78 \%$ of 


\section{O'Brien - Do They Really "Know Nothing"? An inquiry into ethnobotanical knowledge of students in Arizona, USA}

the students). Other popularly named plants like the palo verde, mesquite, ocotillo and cholla were identified less frequently than the saguaro. The palo verde was identified by $42 \%$, the mesquite by $40 \%$, ocotillo by $39 \%$, and the cholla by only $2 \%$. This phenomenon of naming versus recognizing was studied extensively by Gatewood (1983) who argued that verbal based learning has a dominant role in education today, so one is able to learn the name or how to recognize a referent in a vicarious way, such as seeing it on the Internet or by hearing it talked about on the television (Gatewood 1983). In that sense, Gatewood suggests that today, learning to talk about a referent is more important than knowing specific knowledge about that referent. This is reflected in the weak associations between how students learn about plants and identification scores. So from this standpoint, names and identification need not be transmitted through experience-based learning or intimate familiarity necessarily. Students may have named the cholla as a plant because they had heard its name during conversations. For example, nearly everyone I met had a story about accidently walking into a cholla and having to remove the painful barbed glochids from their skin. There also happens to be a street of the same name, Cholla Street, in downtown Ajo.

Open ended interview questions asking participants ecological knowledge about these plants revealed that much of what the students knew was limited to theoretical knowledge such as naming or recognizing something in a video rather than in-depth or culturally-based knowledge such as harvesting or medicinal uses. For example, the majority of students have never eaten mesquite beans or a cactus fruit and even fewer knew when the plants should be harvested. Interestingly, even though in-depth plant knowledge was limited in most students, a few used binomial folk taxonomic rankings such as "rain tree" for creosote since it releases a fragrant resin from its leaves immediately before and during desert rains. The name "bean tree" was often used for the mesquite tree since in the past its seed pods were an important food source. Interestingly, both of these binomial names indicate specific ecological and cultural knowledge about these plants, yet the practical meaning has been lost. It has been noted that binomial folk names encode valuable ecological information about culturally salient species and when descriptive names are no longer used the knowledge they transmit fades as well (Hill 2003, Nabhan 2000). Evidence that specific names are no longer being learned was evident during the identification exercise when it was common for students to recall when and where they usually see a plant "on my way to school" or "in my grandma's backyard" but did not know the name of the plant.

Since it was hypothesized that media would be named as the primary transmitter of ecological knowledge, it was surprising that students named people as transmitters more often than media. Forty-eight percent of participants reported learning about plants primarily by people, followed by school (16\%), and experience (16\%). Media (including television, books, and Internet) only comprised a total of $17 \%$. Comparing scores of students who learn from people or experience versus students who learn through school or media, students who named people or experience had higher identification scores. People are still seen as primary transmitters of ecological information in Ajo perhaps due to its small population with close social ties. Students often named specific people outside of their family who they would ask such as a neighbor who works as a park ranger. This indicates close social networks and an advanced understanding by the students of how to access knowledge through such networks.

Another possible explanation for differences between these findings and other researchers could be due to the methodological approach. Because the open-ended questions, such as "How do you learn?" followed the desert plant identification exercise, participants may have been primed to answer this question in relation to how they learn about desert plants, rather than generally how they learn about the environment. It may be that children still learn about the desert from people since Ajo is a rural area with an above average access to open desert, and about nature or plants and animals more generally from television, books, or the Internet. Since their free lists were comprised of $58 \%$ non-native items, it indicates that students learned the names of these items from a source other than direct experiences in the desert. One of the commonly named non-native items was the redwood tree, which was also a commonly named non-native item in Cooper's South Carolina study (Cooper 2008). Finally, although Internet is available in Ajo, many of the students do not have access to a computer in the household, which could be why more students did not name Internet as a way they would find out about the desert. The local library offers computer and Internet use, but this is limited to four computers and there is often a long waiting line to use them.

Students reported vertical transmission for learning botanical knowledge and had a low frequency of naming peers or siblings, which is similar to other studies (Lozada et al. 2006, Ohmagari \& Berkes 1997). This could again be due to the methodological approach that asked participants to self-report how they learn. In self-reports, people tend to overestimate vertical learning (Bernard 2002). Nevertheless, through the course of the interviews, I found that peers play an important role in the opportunities for exposure to nature. For instance, many of the students only go out into the desert if accompanied by their friends. During free time, they are more likely to go quading or camping in the desert with a friend than by themselves. During my weekly observations at the Ajo Community Center and local parks, I rarely saw students playing alone, but rather they were accompanied by three or four friends or siblings. So, the importance of shared experiences such 
as play time for learning should not be underestimated (Rogoff 2003).

Another surprising finding was that grandparents living in the household did not have a positive association with identification scores but rather, it had a negative one. Previous research conducted in Ajo in the summer of 2004 revealed that high unemployment in the region had prompted many students' parents to migrate to urban centers for jobs and leave children with a grandparent or other elder family member as the primary caregiver (O'Brien 2005). In this situation, children would have the opportunity for more contact with a grandparent, which could, in turn, increase the amount of learning that takes place between generations. In many subsistence based cultures grandparents and other family elders are the primary transmitters of ethnobotanical knowledge. An explanation for the lack of association between having a grandparent in the home and higher identification scores could be due to a change in the social function of the grandparent. In the past, a grandparent often assumed the role of nurturer or temporary caregiver, freeing up their time for activities such as taking their grandchildren out in the garden or telling them stories. However, in the current economy, their new role as primary caregiver leaves them acting less like grandparents and more like parents, stressed with the burdens of raising yet a second generation of children in addition to working a job outside the home. So, although increased contact with the younger generation does support the social conditions necessary for cultural transmission of knowledge, this transmission may not be occurring due to role changes in the older generation. In this regard, it is important to compare ethnographic detail together with quantitative data to explain how shifting economies can change social learning environments in unanticipated ways.

Students in Ajo, unlike their urban counterparts, have easy access to nature with miles and miles of open desert surrounding the small rural town. So rather than a lack of access, it may be lack of motivation to learn about nature that is driving the decline in plant-based knowledge. With Ajo's various economic shifts from a frontier settlement dependent upon cattle ranching, to a company mine town, and in recent years to tourist and service focused industry, the motivations to learn environmental information have changed as future job opportunities become less dependent upon knowledge about the desert environment. When talking to students, I often asked them about their plans after graduation. They would comment 'get out of here' or 'go to Phoenix' to work in a store or a business because 'that is where all of the jobs are' (O'Brien 2008). There is also a cultural belief that the urban centers outside of Ajo bring more opportunity and a modern lifestyle. Among these students in Ajo, there is a perception that in order to make money, progress, or succeed, one needs to go to an urban area to secure a job, which may not be dependent upon knowing any environmental knowledge.
A final note on environmental learning involves the attitude of parents and grandparents. During the course of my time in Ajo, people would often inquire about my research and I would explain that I was studying what children know about the Sonoran Desert. Nine times out of ten they would respond, "Oh, that's easy. I can tell you right now, they know nothing!" I eventually began to wonder what kind of effect this attitude was having on children's knowledge. If their parents or grandparents have already given up on them, then how will children be motivated to learn? Although students would often mention that they had seen specific plants at their grandparent's house or garden, whether the older generation is still trying to teach their children and grandchildren about desert plants should be further investigated. Ohmagari and Berkes (1997) attributed loss of plant skills and knowledge among the Western James Bay Cree in part to a loss of contact between children and elders and an undervaluing of elder's knowledge. But this relationship can work both ways. A negative perception of the younger generation tends to perpetuate itself, starting a cycle that is hard to break. This eventually leads to a decrease in cultural transmission and in overall knowledge across all generations.

\section{Recommendations and Conclusions}

Following the logic that hands on contact and intimate experience with the natural world helps to build one's own conservation ethic, it is important for children to learn about local species since they will ultimately become the managers of their natural resources. Since the students in this study identified people as important sources of ecological information, a project that brings community elders or individuals who work directly with the natural environment into classrooms in order to tell stories about the local environment and share other expertise would address these key findings. Students have close social networks within the community and an advanced understanding of how to access knowledge through such networks. Further research using social network analysis is needed to study how specific ecological information is transmitted.

Educational programs should focus on incorporating hands-on activities that combine local cultural and ecological knowledge into school curriculum. For example, an explanation and demonstration of the ritualistic harvesting of cactus fruit by the Tohono O'odham could be used to teach the life cycle of the saguaro plant. This type of curriculum would teach students the science of desert ecology while establishing a sense of cultural history to the local landscape. Such hands-on activities could entail using nearby parks as outdoor classrooms and/or utilizing green space on or near the school grounds to construct small gardens or plant trails. It is still possible to design naturebased learning even if funds are not available for field trips or gardens. For example, Cooper (2009) surveyed four school campuses in South Carolina for plants and found 


\section{O`Brien - Do They Really "Know Nothing"? An inquiry into ethnobotanical knowledge of students in Arizona, USA}

a high level of diversity including many wild, uncultivated local species which could be used to teach students about local ecology during science classes.

More United States based studies are needed on local plant knowledge. Such studies are important because patterns of delocalization of resources and loss of knowledge are happening worldwide and what we find in the United States may provide insight and predictability into how these changes will play out in other countries. Second, such studies may highlight a cultural shift in how children learn about the natural environment, with formal settings such as school or watching nature-based television programs quickly replacing experiential learning. Future studies on botanical knowledge should identify knowledge change or loss as well as shifts in cultural transmission and free time activities. It is not as important to determine whether free time activities are indoor or outdoor as it is to describe the quality of these activities. Simply being outside does not make one absorb knowledge about local plants. Students in this study spend a great deal of time outdoors on skateboards and ORVs, which make it easy to miss local vegetation. Students described seeing many of the plants while riding in cars in the desert, which could explain the salience of larger plants that are easier to see from the window of a car. Activities such as GPS caching engage children's senses outdoors much the way hunting does and should be further explored as experience based environmental education tools.

Most importantly, future botanical studies should include ethnographic background on the study participants and the community in which they live. Previous research on botanical knowledge has used the term "culturally salient" without any investigation into describing the social aspects of the culture. The economic history of the local community, including how the community's subsistence base has changed, can lead to changes in motivations or opportunities to learn via direct experience. Without such ethnographic context one is left to blindly interpret quantitative results missing the social complexity in which social learning takes place. Ethnobotanical research has the potential to inform educators of the existing knowledge base, which could be used as a foundation to create future educational programs. Such studies will not only help us to better understand the processes of change but may also be a call to action to design curriculum that emphasizes more place-based experiential methods that integrate media and various forms of classroom technology with learning about local species.

\section{Acknowledgements}

I would like to thank the community of Ajo. student participants, and the Ajo Unified School District including Robert Dooley, Don German, and Terry Orr who helped to facilitate my research. Lorraine Eiler, Irma Barajas, Janet
Castro, Andy Fisher and Dr. Linelle Wagner provided expertise and insights. My research associates Mike Foster, Griselda Sandoval, Faye Miller, and Jessica Piekelick were invaluable during the research and interview process. I would also like to thank my dissertation committee Drs. Elois Ann and Brent Berlin and Ted Gragson who advised me on this research. A special thanks to the anonymous reviewers for the comments and suggestions, and to Tammy Watkins and Nicole Fabricant for reading earlier versions of this manuscript. This project was generously funded by the National Science Foundation Doctoral Dissertation Grant and the Canon National Parks Conservation Scholarship.

\section{Literature Cited}

Basso, K. 1984. Stalking with stories: Names, places and moral narratives among the Western Apache. Pp.19-53. in Text, Play, and Story: The construction and reconstruction of self and society. Edited by E. Bruner. American Ethnological Society, Washington, DC.

Berlin, B. 1972. Speculations on the growth of ethnobotanical nomenclature. Language in Society I:5186.

Berlin, B. 1992. Ethnobiological Classification: Principles of categorization of plants and animals in traditional societies. Princeton University Press, Princeton, New Jersey.

Bernard, R. 2002. Research Methods in Anthropology: Qualitative and quantitative approaches. Third Edition. AltaMira Press, Walnut Creek, California.

Borgatti, S.P. 2002. ANTHROPAC 4.983. Analytic Technologies, Columbia, South Carolina.

Cooper, C.L. 2008. Botanical knowledge of a group of South Carolina elementary school students. Ethnobotany Research \& Applications 6:121-127.

Cooper, C.L. 2009. Integrating Schoolyard Flora into the First Grade Science Curriculum. M.S. Thesis (Master's in Earth \& Environmental Resources ManagementM.E.E.R.M.), School of the Environment, University of South Carolina, Columbia, South Carolina.

deMunck V.C. \& E.J. Sobo. 1998. Editors of Using Methods in the Field: A practical introduction and casebook. AltaMira Press, Walnut Creek, California.

Dobyns, H.F. 1972. The Papago People. Indian Tribal Series, Phoenix.

Donald, M. 1991. Origins of the Modern Mind: Three stages in the evolution of culture and cognition. Harvard University Press, Cambridge. 
Dougherty, J. 1978. Salience and relativity in classification. American Ethnologist 5:66-80.

Dougherty, J. 1979. Learning names for plants and plants for names. Anthropological Linguistics 21:298-315.

Fontana, B.L. \& J.P. Schaefer. 1981. Of earth and little rain: the Papago Indians. Northland Press, Flagstaff, Arizona.

Fleisher, M. \& J. Harrington. 1998. Using Methods in the Field: A practical introduction and casebook. Altimira Press, Lanham, Maryland.

Gatewood, J.B. 1983. Loose Talk: Linguistic competence and recognition ability. American Anthropologist 85(2):378-387.

Godoy, R., N. Brokaw \& D. Wilkie. 1998. Of trade and cognition: Markets and the loss of folk knowledge among the Tawahka Indians of the Honduran rain forest. Journal of Anthropological Research 54:219-233.

Gordillo, G. 2004 Landscapes of Devils: Tensions of place and memory in the Argentinean Chaco. Duke University Press, Durham, North Carolina.

Guest, G. 2002. Market integration and the distribution of ecological knowledge within an Ecuadorian fishing community. Journal of Ecological Anthropology 6:38-49.

Heckler, S. 2002. Traditional ethnobotanical knowledge loss and gender among the Piaroa. Pp. 532-548 in Ethnobiology and Biocultural Diversity: Proceedings of the seventh international congress of ethnobiology. Edited by J.R. Stepp, F. Wyndham \& R. Zarger. University of Georgia Press, Athens, Georgia.

Hill, J.H. 2003. What is lost when names are forgotten? Pp. 161-184 in Nature Knowledge: Ethnoscience, cognition, and utility. Edited by G. Sanga \&. G. Ortalli. Berghahn Books, New York.

Holmes, R.M. 1998. Fieldwork with Children. Sage Publications, Thousand Oaks, California. .

Hunn, E.S. 1999. Size as limiting the recognition of biodiversity in folkbiological classifications: One of four factors governing the cultural recognition of biological taxa. Pp. 47-70 in Folkbiology. Edited by D.L. Medin \& S. Atran. Bradford Book, MIT Press, Cambridge, Massachusetts.

Hunn, E. 2002. Evidence for the precocious acquisition of plant knowledge by Zapotec children. Pp. 604-613 in Ethnobiology and Biocultural Diversity: Proceedings of the seventh international congress of ethnobiology. Edited by J.R. Stepp, F. Wyndham \& R. Zarger. University of Georgia Press, Athens, Georgia.
Johnson, J.C. \& D.C. Griffith. 1998. Visual data: Collection, analysis and representation. in Using Methods in the Field: A practical introduction and casebook. Edited by V.C. deMunck \& E.J. Sobo. AltaMira Press, Walnut Creek, California.

Kellert, S.R. 2002. Experiencing nature: Affective, cognitive, and evaluative development in children. Pp. 117-51 in Children and Nature. Edited by P.H. Kahn, Jr. \& S.R. Kellert. MIT Press, Cambridge.

Krech, S. III 2005. Reflections on conservation, sustainability, and environmentalism in indigenous North America. American Anthropologist 107:78-86.

Louv, R. 2006. Last Child in the Woods: Saving our children from nature-deficit disorder. Algonquin Books, Chapel Hill, North Carolina.

Lozada, M., A. Ladio \& M. Weigant. 2006. Cultural transmission of ethnobotanical knowledge in a rural community of Northwestern Patagonia, Argentina. Economic Botany 60:374-385.

Nabhan, G.P. 1994. Children in touch, creatures in story. Pp. 77-108 in The Geography of Childhood: Why children need wild places. Edited by G.P. Nabhan \& S. Trimble. Beacon Press, Boston.

Nabhan, G.P. \& S. St. Antoine. 1993. The loss of floral and fauna story: The extinction of experience. Pp. 229-250 in The Biophilia Hypothesis. Edited by S. Kellert \& E.O. Wilson. Island Press, Washington, DC.

Nabhan, G.P. 2000. Interspecific relationships affecting endangered species recognized by O'odham and Comcaac cultures. Ecological Applications 10(5):1288-1295.

Nabhan, G.P. 2002. Coming Home to Eat: The pleasures and politics of local foods. W.W. Norton \& Company, New York.

O'Brien, C.M. 2005. Birds, Bugs, and Dangerous Animals: Children's acquisition of environmental knowledge in the Sonoran Desert. Presentation in Emerging Issues Along Urban/Rural Interfaces: Linking science and society conference. Atlanta, Georgia, March 21-25, 2005.

O'Brien, C.M. 2008. Ethnobiological Knowledge in the Sonoran Desert: Identifying intergenerational learning and variation. Ph.D. dissertation. University of Georgia, Athens, Georgia.

Ohmagari, K. \& F. Berkes. 1997. Transmission of indigenous knowledge and bush skills among the Western James Bay Cree women of subarctic Canada. Human Ecology 25(2):197-222. 


\section{O'Brien - Do They Really "Know Nothing"? An inquiry into ethnobotanical knowledge of students in Arizona, USA}

Pergams, O.R.W. \& P.A. Zaradic. 2006. Is love of nature in the U.S. becoming love of electronic media? Journal of Environmental Management 80:387-393.

Pergams, O.R.W. \& P.A. Zaradic. 2008. Evidence for a fundamental and pervasive shift away from nature-based recreation. Proceedings of the National Academy of Sciences 105:2295-2300.

Quinlan, M. 2005. Considerations for collecting freelists in the field: Examples from ethnobotany. Field Methods $17: 219-234$

Raffles, H. 2002. Intimate knowledge. International Social Science Journal 173:325-334.

Reyes-García V., V. Vadez, T. Huanca, W.R. Leonard \& T.W. McDade. 2007. Economic development and local ecological knowledge: A deadlock? Data from a native Amazonian society. Human Ecology 35(3):371-377.

Rogoff, B. 2003. The Cultural Nature of Human Development. Oxford University Press, New York.

Roseman, M. 1998. Singers of the landscape: Song, history, and property rights in the Malaysian rain forest. American Anthropologist 100:106-121.

Ross, N. 2002. Cognitive aspects of intergenerational change: Mental models, cultural change, and environmental behavior among the Lacandon Maya of Southern Mexico. Human Organization 61(2):125-138.

Sheridan, T.E. 2000. Human ecology of the Sonoran desert. Pp. 105-118 in A Natural History of the Sonoran Desert. Edited by S.J. Phillips and P. Wentworth Comus. Arizona-Sonoran Desert Museum, Tucson.
Spradley, J.P. 1979. The Ethnographic Interview. Holt, Rinehart, and Winston, New York.

Stross, B. 1973. Acquisition of botanical terminology by Tzeltal children. Pp. 107-141 in Meaning in Mayan Languages. Edited by M.S. Edmonson. Mouton, The Hague.

Tull, D. 1994. Elementary students' responses to questions about plant identification: Response strategies in children. Science Education 78:323-343.

U.S. Census. 2000. Census of Population and Housing for Ajo, Arizona. U.S. Bureau of Census, Washington, D.C.

Wagner, G. 2008. Botanical knowledge of a group of college students in South Carolina, U.S.A. Ethnobotanical Research \& Applications 6:443-458.

Weller, S.C. \& A.K. Romney. 1988. Systematic Data Collection: Quantitative research methods. Sage Publications, Thousand Oaks, California.

Witkowski, S.R., C.H. Brown \& P.K. Chase. 1981. Where do tree terms come from? Man (n.s.) 16:1-14.

Zarger, R.K. \& J.R. Stepp. 2004. Persistence of botanical knowledge among Tzeltal Maya children. Current Anthropology 45(3):413-418.

Zent, S. 2001. Acculturation and ethnobotanical knowledge among the Piaroa of Venezuela: Demonstration of quantitative method for the empirical study of TEK change. Pp. 190-211 in Language, Knowledge, and the Environment. Edited by L. Maffi. Smithsonian Institution Press, Washington, DC. 
